\title{
O CAMPO DAS POLÍTICAS PÚBLICAS DE EDUCAÇÃO: UMA REVISÃO DA LITERATURA
}

ANGELA MARIA MARTINS

\section{RESUMO}

A revisão de literatura no campo das políticas públicas e, particularmente, no que diz respeito às políticas educacionais, indica a necessidade de aprofundamento do debate em torno de aspectos teóricos e metodológicos presentes na produção de pesquisas. Assim, este artigo discute, primeiramente, questões sinalizadas por estudiosos sobre origens e problemas na construção do campo disciplinar das políticas públicas para em seguida apontar elementos convergentes em balanços de literatura realizados por pesquisadores da educação, que há algum tempo assinalam fragilidades e potencialidades de estudos nessa área do conhecimento. Finalmente, discute-se que parte das pesquisas não consegue superar, ainda, o dilema da ausência de articulação entre as diferentes dimensões que compõem a análise das políticas educacionais.

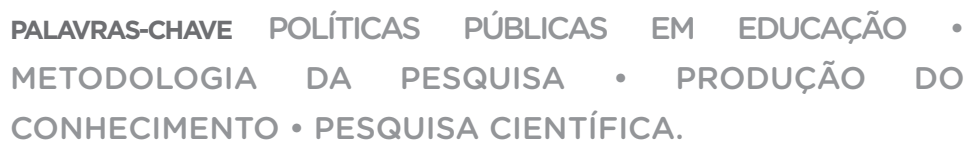




\title{
RESUMEN
}

La revisión de literatura en el campo de las políticas públicas, sobre todo en lo que concierne a las políticas educacionales, indica la necesidad de profundizar el debate en torno a aspectos teóricos y metodológicos presentes en la producción de investigaciones. De este modo, este artículo discute en primer lugar temas señalados por estudiosos sobre los orígenes y los problemas para construir el campo disciplinario de las políticas públicas para en seguida subrayar elementos convergentes en balances de literatura realizados por investigadores de la educación, que hace algún tiempo destacan fragilidades y potencialidades de los estudios en dicha área del conocimiento. Finalmente, se discute que una parte de las investigaciones todavía no logra superar el dilema de la ausencia de articulación entre las distintas dimensiones que componen el análisis de las políticas educacionales.

PALABRAS CLAVE POLÍTICAS PÚBLICAS EN EDUCACIÓN • METODOLOGÍA DE LA INVESTIGACIÓN • PRODUCCIÓN DEL CONOCIMIENTO • INVESTIGACIÓN CIENTÍFICA.

\begin{abstract}
A review of the literature in the field of public policies, especially regarding education policies, points to the need for a more in-depth debate on the theoretical and methodological aspects concerning research production. Therefore, this paper discusses, first of all, what scholars identified as issues on the origins and problems on the construction of the disciplinary field of public policies. It then points out converging elements in the review of the literature carried out by education researchers, who have been identifying weak points and study opportunities in that field for some time. Lastly it discusses the fact that some of the researches have not yet been able to overcome the dilemma of the absence of communication among the different dimensions that constitute the analysis of education policies.

KEYWORDS PUBLIC EDUCATION POLICIES - RESEARCH METHODOLOGIES • PRODUCTION OF KNOWLEDGE • SCIENTIFIC RESEARCH.
\end{abstract}


1 A dimensão polity se refere à estrutura jurídica, político-administrativa e ao sistema político de um país politics são os processos políticos, permeados de negociações políticas conflituosas para formulação de objetivos e temas da agenda; a dimensão policy se refere aos conteúdos da política, materializados em programas de governo, com metas e objetivos a serem cumpridos por meio de ações/ atividades/dinâmicas definidas. Ver a discussão realizada adiante.

2 Ver as discussões realizadas por Faria (2003); Souza (2003, 2006); Frey (2000)

3 Registre-se que o texto de Figueiredo e Figueiredo (1986) tornou-se marco em alguns estudos na área da educação. Entretanto, artigo em pauta, embora procure apontar tendências no debate sobre "avaliação política e avaliação de políticas", não esclarece diferenças desses termos em relação à "análise política e análise de políticas", sendo as expressões usadas de forma correspondente. Recentemente, a utilização de modelos estatísticos tem sido intensificada, sobretudo aqueles advindos da econometria,

consolidando a terminologia "avaliação de políticas". Sem adentrar nas controvérsias, Souza (2006) afirma que essa vertente pode ser uma subárea no campo

da análise de políticas, mais focada nos programas, projetos, planos e demais medidas que concretizam as políticas públicas e que exigem monitoramento e avaliação.

\section{A ANÁLISE DE POLÍTICAS PÚBLICAS: ORIGENS E NOÇÕES}

Alguns trabalhos elaborados na área das políticas públicas apresentam aspectos comuns que merecem destaque. O primeiro deles se refere à sua emergência, por volta de 1958, nos Estados Unidos (EUA) - sob a denominação de policy science ${ }^{1}$ - em função de problemas econômicos, financeiros e sociais enfrentados pelo mundo ocidental desenvolvido, cuja crise explicitou as dificuldades do poder público. ${ }^{2}$

Uma preocupação instalada no campo científico buscava fornecer aos policy makers - fazedores de políticas - ferramentas e instrumentais para enfrentar os desafios do desenvolvimento pós II Guerra Mundial. Entretanto, outra perspectiva buscava ampliar as possibilidades de análise nesse campo, a construção de um campo disciplinar e a acumulação de conhecimento. Esse movimento pendular talvez perdure até o presente momento - embora com outras características - juntamente com as diferentes visões que fundamentam a polêmica em torno da definição dos termos "análise de políticas, análise para políticas, avaliação política e avaliação de políticas". ${ }^{3}$ 
Construiu-se, gradativamente, o campo disciplinar de políticas públicas em cursos universitários, concomitantemente às ações de agências de governo que passaram a contratar analistas políticos, na função de especialistas que integravam e/ou assessoravam suas equipes na realização de análises de custo-benefício, de orçamentos por programa e de análises de impacto. Nesse início, muitos dos programas de pós-graduação tomaram emprestados os modelos da administração de empresas, com ênfase nos métodos quantitativos aliados à análise organizacional, estes baseados em estudos de caso. Dessa forma, instaurou-se um debate que mudou a escala de interesses, ou seja, de meados dos anos de 1950 até a década de 1970, a preocupação científica pelo tema aumentou significativamente, consolidando um campo disciplinar, considerado, em princípio, como uma subárea da ciência política. ${ }^{4}$

4 Além dos autores citados anteriormente, ver também a

Outros autores assinalam ainda que, na Europa, esses estudos surgiram na Alemanha, a partir dos anos de 1970, com cussão de literatura elaborada por a ascensão da social democracia ao poder e a consolidação dos mecanismos de planejamento e cobertura das políticas setoriais (FREY, 2000).

Entretanto, Souza (2006) aponta elementos relevantes nas diferenças sobre as origens desse campo do conhecimento em duas realidades distintas: EUA e Europa. Para a autora, nos EUA, a disciplina acadêmica tem sua origem pulando etapas teóricas de análises sobre o Estado e suas instituições - preocupação tradicionalmente europeia passando a focar os estudos na ação dos governos. Nessa perspectiva, a autora assinala que o pressuposto existente no processo de construção desse campo de conhecimento dizia respeito ao funcionamento das democracias estáveis, permeado da ideia de que as acões do governo poderiam ser planejadas cientificamente e reformuladas por investigadores independentes. Nesses termos, nos EUA, construiu-se e consolidou-se uma tendência de estudos dedicados a examinar o mundo político, com foco na preocupação de procurar entender o que os governos fazem, porque e para quem eles fazem, ou ainda, em outras palavras, quem ganha e quem perde nas decisões de governo. 
5 Não entrarei nas peculiaridades que cercam a produção latino-americana no que diz respeito às teorias que vêm fundamentando estudos sobre políticas públicas nessa região. Entretanto, alguns autores foram tomados como referência em parte dos estudos realizados, dentre os quais, ressalte-se a obra de O'Donnell (1986, 1988, 1990), que analisa as características do Estado burocrático-autoritário na América Latina.

6 Ver a discussão realizada por Souza (2006) sobre os teóricos precursores no campo das políticas públicas.
O segundo aspecto diz respeito às diferentes visões existentes na polêmica sobre contribuições das diversas disciplinas para a construção do campo de políticas públicas, bem como a própria definição dos termos utilizados nas pesquisas.

Nesse sentido, sem perder de vista suas origens na ciência política, registre-se que esse é um campo que agrega conhecimentos advindos de diferentes disciplinas - economia, política, sociologia, antropologia, geografia, planejamento, gestão e ciências sociais aplicadas -, compondo uma subárea de estudos que tinha como propósito subsidiar a solução de problemas provocados pela ação do Estado, bem como entender suas causas e consequências, condicionadas por um contexto específico em determinado espaço de tempo.

Frey (2000) sublinha as características que configuraram seu surgimento, definidas pela necessidade de se construir conhecimentos que unissem teoria à prática. Em outras palavras, a busca de explicar a prática política por meio da empiria teria levado à definição de alguns dos modelos encontrados nas origens desse campo científico, baseados numa visão racional de política e focados na dinâmica de governos democráticos estáveis dos países centrais. Assim, a transposição de uma determinada visão de Estado, de sociedade, de políticas públicas e de análise das políticas públicas - configuradas em determinado período histórico e em condições específicas ainda constitui um dos principais desafios a serem superados nas pesquisas desenvolvidas em países periféricos. ${ }^{5}$

Outro aspecto se refere à questão das decisões registradas em agendas de governo, articuladas em determinado período histórico, negociadas por entrelaçamentos de interesses no cenário contemporâneo, que amplia a complexidade de entendimento sobre o que o governo faz, para quem e por que, pois coloca em evidência novos atores sociais: ${ }^{6}$ o Estado, que abriga grupos de interesses de funcionários públicos; organizações não governamentais, entidades sindicais e grupos representativos de interesses específicos, tais como os que defendem o direito às diferenças etc. Assim, as políticas públicas são traduzidas em ações que se realizam em processo, durante o qual negociações são encetadas e grupos em conflito influenciam a agenda de governo. Nessa perspectiva, os 
processos de implementação assumiriam maior importância do que as formulações de agenda, pois é no seu decorrer que as políticas ganham dinâmica, mudam, são reorientadas e renegociadas (FREY, 2000; MARTINS, 2011b).

Em outras palavras, políticas mudam com o tempo - as intenções de ontem já não são as mesmas de hoje -, ações implementadas sofrem mudanças de valores no decurso de um mesmo governo, configurando-se como processos dinâmicos, cuja complexidade de análise exige mais do que modelos e/ou estatutos teóricos que possam explicar escolhas feitas e já não mais vigentes. ${ }^{7}$

Aqui cabe um destaque. Na realidade, se há convergência de ideias na literatura examinada em relação às origens das pesquisas em políticas públicas e às diferentes concep7 Ver também a discussão realizada por Ham e Hill (1993). Os autores se reportam a diversos teóricos da área para estruturar um painel sobre as diferentes concepções que prevalecem referentes a essa discussão. ções emergentes nesse contexto, não há menção específica ao sistema político e econômico implantado com base em Bretton Woods (1944), cenário no qual foram construídas as categorias usadas nas teorias e investigações no campo mais amplo das ciências sociais, até os anos de 1980 e que expressam as contradições inerentes ao funcionamento das democracias ocidentais. Como não existe construção de conhecimento desvinculado de processos históricos, políticos e sociais que o engendrou, ressaltem-se as principais características do período pós II Guerra Mundial.

As lutas e reivindicações de trabalhadores organizados em sindicatos e centrais sindicais até meados do século XX - tanto em países localizados na Europa central como nos Estados Unidos - não foram acolhidas e implementadas por regimes e/ou partidos social-democratas, pois a influência destes no cenário político institucional dos países centrais era completamente marginal. As reivindicações foram atendidas, em sua maioria, por governos liberais, que constituíram mecanismos de gestão das políticas públicas, canalizando as reivindicações dos trabalhadores e incorporando boa parte delas na pauta de suas agendas. O teor predominante nessas demandas era promovido às vezes por partidos e sindicatos - ainda alinhados à ortodoxia soviética - ou por sindicatos autônomos, alinhados a movimentos independentes e/ou autogestionários. 
Assim, os direitos sociais de cidadania construídos nas democracias industriais até os anos 1940 conferiram status civis (direitos legais) e políticos (direitos de participação democrática) quase sem implicações para a economia e foram substituídos por direitos sociais que estabeleceram padrões de acesso à saúde, à renda, à educação, aos direitos trabalhistas e previdenciários. Conceitos e termos usados em pesquisas realizadas nesse período no campo das ciências sociais podem ser assim resumidos: construção da cidadania; universalismo; soberania nacional; identidade e autodeterminação dos povos; etnias e religiões; sociedade civil, Estado e partidos políticos; sindicatos e movimentos sociais; autonomia regional; opinião pública; povo, classe social, hegemonia e igualdade.

A partir dos anos 1980, entretanto, esses conceitos passaram a ser desafiados na medida em que haviam sido elaborados em contexto no qual sociedades nacionais eram detentoras de soberania. A mudança nas estruturas sociais e econômicas reorganizou radicalmente a natureza da democracia ocidental. Essa sobrecarga de demandas - da qual derivaria um dos fatores de crise das sociedades mais avançadas - é uma das características centrais dos regimes democráticos, pois o denominado Estado de serviços, fortemente burocratizado, foi, historicamente, uma resposta às demandas organizadas e populares pós II Guerra Mundial. Atualmente, "[...] se sustenta que o fruto era venenoso, mas deve-se reconhecer que a árvore não podia dar frutos diferentes [...].” (BOBBIO, 2000, p. 138).

Em outros termos, desde os anos 1980, o mundo assistiu à reestruturação do papel e das funções do Estado, à redefinição das condições de produção material e simbólica da vida e ao colapso do ideário marxista alinhado às teses soviéticas. Em consequência, a pauta das pesquisas realizadas na área das ciências sociais foi sendo modificada gradativamente. Os estudos passaram a explorar temas tais como: as tensões nas relações entre trabalho e emprego e a emergência de novas ocupações; a crise de identidades profissionais, pessoais e coletivas; as trajetórias de formação e as diferentes formas de inserção no mundo do trabalho, evidenciando os 
processos de transição social, a instituição e a destituição de profissões; a relativização do trabalho como eixo identificatório; o direito à livre orientação sexual e religiosa; os valores éticos e morais; as novas dinâmicas familiares; em suma, o direito a ser diferente em contexto adverso do ponto de vista econômico e social.

No campo da análise de políticas públicas, as tensões entre a reestruturação do mercado e do mundo do trabalho - com forte movimento de privatização dos serviços sustentados pelo Estado, aliadas à retração fiscal e à constatação dos riscos de crise nos países centrais para enfrentar problemas sociais - ampliaram a utilização, por parte de diferentes governos, de instrumentos, técnicas e terminologias usadas na área da administração de empresas, renovando a trilha seguida em seus primórdios. Esses usos têm sido consolidados recentemente, conforme se discutirá na parte final deste artigo.

\section{QUESTÕES NA CONSTRUÇÃO DO CONHECIMENTO EM POLÍTICAS PÚBLICAS}

Pesquisadores do tema assinalam, há algum tempo, problemas na construção, acumulação e consolidação de conhecimentos nessa recente subárea de estudos. De acordo com Souza (2003), nas pesquisas em políticas públicas no Brasil, uma questão relevante a ser apontada diz respeito ao crescimento da produção científica mais em torno de áreas temáticas do que em torno de linhas e/ou grupos de pesquisa consolidados. A autora assinala que investigações preocupadas em abranger temas mais amplos e/ou articulados não são comumente encontradas nesse campo, tais como: o papel das burocracias responsáveis pela implementação das políticas públicas; ausência de modelos fundamentados na teoria das elites ou das redes sociais; estudos comparativos entre políticas implementadas por esferas estaduais, tendo em vista que as preocupações se voltam aos governos locais e à esfera federal. Frey (2000), da mesma forma, sinaliza que o foco das pesquisas recaiu na análise de estruturas e instituições ou se restringiu aos aspectos que envolvem os processos de negociação de políticas setoriais, baseados em seus efeitos, 
adotando modelos descritivos com diferentes e, muitas vezes, frágeis graus de complexidade metodológica e analítica.

É preciso salientar, entretanto, que seja qual for o modelo adotado, as investigações necessitam de um bom embasamento teórico, pois sem esse pressuposto não há como gerar boas análises e generalizar resultados. Nessa perspectiva, registre-se que mais recentemente renovou-se a trilha adotada inicialmente nesse campo de investigação, lançando-se mão de modelos estatísticos mais sofisticados. Entretanto, sem o domínio de teorias que permitam examinar com profundidade as relações entre Estado, sociedade e política - apenas para retomar a ideia original de construção do próprio campo - torna-se tarefa difícil ampliar e consolidar conhecimentos significativos. Contudo, vale a pena tecer algumas considerações sobre a complexidade que permeia a construção de um campo científico para tornarmos esse debate mais ponderável.

O envolvimento da comunidade acadêmica em torno de uma agenda de pesquisa que estruture, amplie e consolide o conhecimento sobre as políticas públicas não ocorre de forma linear, tendo em vista as peculiaridades do próprio objeto. Ao contrário, esse processo dinâmico constitui - e concomitantemente é constituído - por dois movimentos que desenham um campo de tensão na área.

O primeiro diz respeito aos recursos envolvidos - tanto em investigações de amplo escopo, como em bolsas individuais de pós-graduação - pautados por três ordens de interesses: governos que definem linhas de financiamento para agências de fomento, muitas vezes, alinhadas aos seus próprios interesses; especialistas que prestam consultorias para as agências de fomento, representando seus pares no campo científico; órgãos governamentais e/ou sem fins lucrativos - nacionais e internacionais - que solicitam assessorias, consultorias e avaliações objetivamente estabelecidas para auferir sucessos, resultados, impactos de programas e projetos.

Esta última ordem de interesses pode tencionar as decisões sobre as dimensões a serem avaliadas, pois a concatenação entre variáveis independentes e dependentes é o que concretiza as políticas implementadas. Em outros termos, 
quando especialistas são chamados por agências de governo para analisar políticas públicas, se veem na contingência de considerar as dimensões da polity e da politics, ${ }^{8}$ como variáveis independentes, isto é, os pesquisadores tomam como 8 Ver a referência a essas noções na primeira página do artigo. ponto de partida que estruturas de poder e de condições não são objeto de discussão. Portanto, as assessorias, de modo geral, se restringem a examinar programas em determinado espaço de tempo, com vistas a otimizar custos/benefícios, a monitorar resultados com foco nos beneficiários, e, quando for o caso, propor reorientações de percurso. Essa redução da complexidade pode ser operacional, isto é, facilita a elaboração de projetos de pesquisa, nos quais as dimensões ficam restritas a aspectos das variáveis dependentes a serem categorizadas, ou seja, a aspectos da policy, com vistas a subsidiar os gestores para possíveis rearranjos de percurso.

Entretanto, não considerar elementos referentes aos arranjos institucionais (conflitos e consensos que pautaram aquela determinada política), aos atores envolvidos (associações, fóruns, conferências, conselhos, órgãos de governo que representam nichos de interesses) e à estabilidade institucional de políticas setoriais que envolvem percentuais orçamentários previstos em lei, pode comprometer os resultados, pois a redução não explica, por si só, fracassos, sucessos, limites, potencialidades, fragilidades, enfim, os motivos pelos quais uma medida/programa/projeto pode ter alcançado melhores resultados ou não. Em suma, para concatenar as dimensões que envolvem variáveis dependentes e independentes, as pesquisas precisariam ter maior abrangência e/ou haveria necessidade de realização de estudos de caso preliminares, o que exigiria somas de recursos razoáveis. Assim, realizar pesquisas, na forma de consultoria, atendendo a demandas de órgãos governamentais tem sido uma das formas viáveis de realização de investigações de grande escopo, o que envolve o risco de se deixar de lado as dimensões da polity e da politics, fundamentais para a compreensão das opções de governo na implementação de seus programas.

$\mathrm{Na}$ mesma direção, deve-se tomar cuidado especial quanto à transformação de pesquisadores em gerenciadores de pesquisas, apenas. Na visão de Ozga (2000), o próprio 
ensino superior encontra-se, atualmente, muito propenso às orientações/demandas de mercado, com a proliferação de pesquisas contratadas por grandes empresas. Nesses estudos, os investigadores não podem perseguir determinadas ideias, mudar o percurso da coleta - procedimento inerente a pesquisas qualitativas que não possuem respostas a priori para problemas gerados em contexto - e interpretar livremente os dados recolhidos, pois o que se espera deles é que coordenem prazos fechados e contratos para responder a objetivos postos pelo interesse do contratante.

Da mesma forma como mudam constantemente as regras de compromisso entre professores, direção e os órgãos centrais dos governos, as agências de financiamento também mudam permanentemente as linhas de incentivo, as especificidades de contrato, a prestação de contas e as prioridades de investimento de acordo com as demandas operadas pelas políticas públicas, processo esse que gera pressões sobre os pesquisadores. A transformação desse processo em rotina de pesquisa potencializa a ansiedade nos estudiosos que “[...] não podem trabalhar reflexivamente: à medida que perdem a capacidade de se envolverem completamente com a investigação, se tornam mais propícios a escutarem os financiadores [...]." (OZGA, 2000, p. 137), limitando-se ao papel de gerenciadores das investigações.

Entretanto, entre as investigações controladas politicamente e as investigações autônomas há que se encontrar um ponto de equilíbrio, pois seria ingenuidade acreditar que pesquisadores independentes sobreviveriam em ambiente acadêmico-institucional sem recursos públicos e/ou privados e alienados do mundo da política. O ponto crucial está no imbricamento entre relações de poder, conhecimento e as finalidades da produção científica. Por exemplo, o desenvolvimento de pesquisas de base pode se beneficiar pelo desenvolvimento de pesquisas aplicadas e instrumentais no âmbito do ensino superior, cujos resultados e/ou produtos destas poderiam gerar novos financiamentos a serem direcionados àquelas. Ambas as modalidades constituem estudos normativos (ainda que nas investigações de base as normas sejam estabelecidas pelos pesquisadores), criam conhecimento e 
influenciam as relações de poder que irão configurar o escopo das políticas públicas a serem implantadas.

\section{QUESTÕES NA ANÁLISE DE POLÍTICAS PÚBLICAS DA EDUCAÇÃO}

A história dos estudos em política educacional está relacionada à teoria das escolhas racionais com vistas a melhorar os serviços públicos e estatais, sobretudo no período pós II Guerra Mundial, quando as teorias do capital humano e os princípios das democracias liberais definiam os caminhos a serem desenhados pelas investigações. Essa visão utópica das possibilidades da educação e os equívocos que cercavam a noção racional e linear da política - quando se acreditava que as ações e programas de governo seriam desenvolvidos exatamente da maneira como haviam sido formulados, promovendo o progresso social - deu lugar a um pessimismo generalizado e a uma visão crítica sobre as contribuições da educação para a constituição de sociedades mais justas e desenvolvidas.

Após os anos 1990, pesquisadores têm se dedicado a examinar o crescimento da produção científica na educação, fato esse constatado por inúmeros trabalhos - elaborados no formato de estado da arte, estado do conhecimento, campo da questão, balanços de teses e de literatura - embora alguns dos estudos de sistematização não indiquem exatamente os pressupostos sobre os quais se assentam seus levantamentos, quais foram os procedimentos adotados para as fontes escolhidas e, mais precisamente, quais são as fontes, tais como teses, artigos acadêmicos, anais de eventos, livros, artigos de livros e relatórios de pesquisa (PAIVA, 1998; WITTMANN; GRACINDO, 2001; AZEVEDO, 2004; AZEVEDO; AGUIAR, 2001; MAINARDES; FERREIRA; TELLO, 2011; MARTINS, 2011a).

Esses levantamentos têm sido críticos em relação aos desenhos metodológicos, sublinhando que as pesquisas nem sempre esclarecem os procedimentos e as técnicas utilizadas, bem como não sustentam as análises com base em aportes teóricos substantivos, o que nos permite inferir que no campo da análise de políticas públicas educacionais, a teoria ainda faz muita falta, como foi dito anteriormente. 
Em suma, as críticas são dirigidas à pouca relação estabelecida entre os propósitos das investigações, o delineamento metodológico, os marcos teóricos e os resultados, bem como à predominância de estudos de caso, em detrimento de investigações de maior escopo.

A literatura examinada aponta, ainda, a quantidade de estudos que lançam mão, primeiramente, de um discurso baseado na análise dos condicionantes estruturais, sobretudo econômicos e políticos, com referências ao neoliberalismo, à globalização, e às diretrizes semelhantes que pautam agendas de diferentes governos. Este pode ser um dos fatores assinalados pelas sistematizações realizadas que ampliariam, talvez, a ideia de que, no escopo das investigações da área, temos mais do mesmo: se as agendas governamentais são homogêneas, as reflexões sobre sua formulação também acabam por se assemelhar.

Registre-se que a facilidade na divulgação e circulação de discursos e instrumentos elaborados em âmbito internacional, por meio das tecnologias de informação, pode influenciar processos decisórios em nível nacional/local, embora reinterpretações sejam feitas nessas localidades. A análise da agenda de governo em diferentes países já indica mais semelhanças do que diferenças, o que faz com que uma parte das investigações nesse campo apresente estrutura semelhante também, privilegiando cenários e contextos políticos, em detrimento da análise de questões específicas, regionais e/ou locais.

É preciso considerar, ainda, que as medidas governamentais atendem a focos específicos de problemas detectados em movimentos políticos e sociais cada vez mais complexos, tendo em vista a pluralidade de demandas dos mais diferentes segmentos. As ações políticas, entretanto, geram um embate decisório entre dois eixos - propostas comuns e soluções diversas - tendo em vista que o encaminhamento do segundo eixo fica por conta das possibilidades institucionais de governos nacionais/regionais/locais, cujas estratégias (e potencialidades econômicas e políticas) são distintas.

Entretanto, na literatura que procura sistematizar os estudos em políticas educacionais, nota-se a ausência de um 
ponto relevante. Não há menção ao fato de que o cenário apontado nas pesquisas, muito provavelmente, não diga respeito à análise política da agenda, quando predominaria o foco sobre negociações e conflitos na estruturação de sua pauta, aspectos esses referentes à dimensão da politics. Infere-se que o contexto acaba compondo, assim, apenas a parte inicial da avaliação/análise de um determinado programa e/ou projeto de governo, sem estabelecer, muitas vezes, maiores articulações com o objeto examinado.

Como foi dito anteriormente, aspectos normativos, programas e projetos de diferentes governos são semelhantes, independentemente de sua localização espacial, o que também pode ampliar a ideia de replicação dos conteúdos políticos examinados. Em suma, a ausência de relações consistentes entre as duas dimensões - da politics e da policy talvez seja um dos maiores problemas existentes hoje nos estudos sobre políticas educacionais, embora não se encontrem referências sobre essa questão. Examinar as duas dimensões extrapola a denominada "discussão de literatura" ou "discussão de contexto" - item largamente encontrado na justificativa/introdução de teses, artigos, relatórios de pesquisa - pois exigiria metodologia específica, vinculando as dimensões anteriormente referidas, que concatenam as políticas públicas.

Souza (2006) sinaliza que o foco analítico da política pública reside na identificação do problema que ela procura solucionar, na forma como esse problema se concretiza no sistema jurídico e político (politics) e na sociedade política (polity). Esse pressuposto - assim como a definição das tipologias - dificilmente aparece nos estudos em políticas educacionais, o que nos leva a inferir que a área nem sempre estabelece diálogos com as teorias e modelos construídos no campo mais amplo da análise das políticas públicas.

Nesse sentido, os estudos em avaliação de políticas educacionais tendem - sobretudo mais recentemente - a centrar seu foco na avaliação de programas e projetos, lançando mão de outras perspectivas teóricas, não localizadas exatamente no campo das políticas públicas. Concordando com Souza (2006), essa vertente pode ser uma subárea no campo da 
análise de políticas, mais focada nos programas, projetos, planos e demais medidas que concretizam as políticas públicas e que exigem monitoramento e avaliação.

Acrescente-se que a educação, ao lançar mão de conceitos das ciências sociais e humanas, transforma, muitas vezes, teorias em slogans (OZGA, 2000), o que pode comprometer muitas das análises realizadas. Embora esse panorama venha sendo modificado gradativamente no cenário contemporâneo, ainda perduram os usos das teorias como peças de encaixe para sustentação de pontos de vista que não encontram respaldo na realidade das redes de escolas.

Contudo, parte da literatura passou a questionar os desenhos metodológicos utilizados na área das políticas educacionais, antes mais voltadas à análise de macro-estruturas, iniciando um movimento de estruturação de investigações dedicadas a examinar aspectos da micropolítica (BALL, 1989, 2006). Assim, estudos voltados a analisar as reformas implementadas desde o início dos anos 1980 - centradas na responsabilização das escolas e de seus profissionais - passaram a questionar as motivações políticas que fundamentam esse processo, adotando abordagens que buscam apreender a visão/opinião/percepção de diretores, professores, coordenadores pedagógicos, pais e alunos sobre as medidas, com vistas a construir percursos mais flexíveis de investigação na área.

Entretanto, romper com os denominados modelos top-down de análise não é tarefa fácil. Esse percurso ainda está sendo trilhado por todos aqueles que buscam o desenho bottom-up, isto é, que procuram analisar a política pública com base na ação dos seus implementadores, contrapondo-se às pesquisas dedicadas a analisar apenas processos decisórios/decisores e gestores de esferas e órgãos centrais.

No campo da educação, o modelo top-down parte do pressuposto de que se o modelo de escola formal é adequado, o ensino e a aprendizagem serão bem sucedidos (OZGA, 2000). Esta perspectiva ainda permanece e está longe de responder às questões insistentes que aparecem em estudos dessa subárea: por que algumas escolas apresentam bons índices de desempenho de alunos e outras não? O que faz com que determinados professores e diretores consigam mobilizar re- 
cursos para implementar um ensino de qualidade e outros não? A simples mensuração de resultados não responde à complexidade dos processos educativos, cujas características são singulares: as unidades escolares e as práticas que ali se desenrolam são permeadas por incertezas, inseguranças e visões de mundo constituídas ao longo das trajetórias profissionais que se defrontam, ainda, com as variáveis das famílias e das comunidades que convivem nesse espaço. Suprimir ou não considerar esse contexto na análise de redes de ensino e unidades escolares - espaço onde convivem diferentes valores sociais manifestos singularmente - é recuperar a noção da política na base do top-down.

Para o redirecionamento nas abordagens metodológicas, destacam-se as contribuições teóricas e metodológicas advindas da antropologia, da sociologia e da ciência política. Tendo em vista a prevalência de estudos qualitativos - boa parte deles realizados como estudos de caso -, o uso de observações (participantes ou não), estudos etnográficos, pesquisa-ação, pesquisa-intervenção vêm sendo assumidos em parte das investigações, ao tempo em que os trabalhos indicam a análise de diretrizes legais e programas oficiais. Esse duplo movimento - análise de conteúdo e estudos de caso - resume o desenho da maior parte das investigações sobre políticas educacionais e gestão da educação (MARTINS, 2011a), o que pode restringir a possibilidade de ampliação do conhecimento na área, em bases mais sólidas. Recentemente, encontram-se trabalhos que lançam mão de dados estatísticos nem sempre suportados por teorias e argumentos consistentes, restringindo-se a descrições.

\section{NOVO CENÁRIO NAS POLÍTICAS PÚBLICAS: NOVAS QUESTÕES?}

Como foi dito anteriormente, após os anos 1980 - em contexto de política fiscal restritiva de gasto - novas formas de gestão e, em decorrência, novas abordagens em políticas públicas foram introduzidas em torno do conceito de governança para resultados, visto como novo paradigma no modelo de gestão pública, denominado pós/neoburocrático/novo 
gerencialismo público, que estaria substituindo os modelos mais racionais de políticas públicas. De modo geral, justifica-se que o Estado contemporâneo vem sendo gerenciado com base em arranjos múltiplos dos quais participam atores muito diversificados: organizações não governamentais; movimentos que defendem os direitos às diferenças; partidos políticos que não conseguem fazer diferenciar suas agendas e/ou plataformas políticas; as razões de mercado; os grupos que atuam dentro dos escalões de governo, formando nichos específicos de interesses etc.

Em outros termos, olhar para essa complexidade - que transforma o Estado em "orquestrador, direcionador estratégico, indutor e fomentador [...] essencial para a ativação e orientação dos demais atores" (BRASIL, 2009, p. 5), exigiria mais do que modelos lineares/burocráticos de avaliação de políticas públicas no presente momento.

Evidencia-se a recuperação de terminologias e noções da área de administração de empresas tais como eficácia; eficiência; efetividade; execução; excelência e economicidade, enquanto dimensões que compõem as avaliações de desempenho, por exemplo; concomitantemente, outras têm sido incorporadas, tais como mecanismos amplos de accountability; controle e permeabilidade; gestão e mensuração do desempenho da gestão pública, compreendida "como resultados a serem alcançados”. A cadeia de valores defendida, entretanto, parece não ser muito diferente do que se propunha no denominado período burocrático: insumos (inputs); processos/projetos (ações); produtos/serviços (outputs); impactos (outcomes) (BRASIL, 2009, p. 9).

Estudos sobre políticas educacionais vêm adotando algumas dessas premissas - embora ainda em número pouco expressivo - nem sempre esclarecendo as tipologias e/ou modelos adotados, prevalecendo o mesmo formato anterior: breve discussão inicial sobre perspectivas apoiadas em pesquisas avaliativas de programas e projetos - lançando mão, portanto, de referenciais completamente diferentes dos que são citados no campo mais amplo das políticas públicas - seguida de sistematização de fontes e/ou dados estatísticos, em alguns casos, baseados em modelos sofisticados. Entretanto, 
o corpo analítico de parte das pesquisas não consegue superar, ainda, o dilema da ausência de articulação entre as diferentes dimensões que compõem as políticas públicas, apontadas anteriormente. ${ }^{9}$

Conforme analisa Souza (2006, p. 36), "o declínio do sonho pluralista que acompanhou o início da estruturação das políticas públicas", sobretudo nos EUA - substituído pela ideia cunhada por Olson (1965), de que os interesses de poucos têm mais chances de se concretizarem do que os interesses de muitos - faz com que contemporaneamente se enfatizem os elementos acima apontados, acrescidos de outros: a credibilidade (ligada à política monetária); a discricionariedade, o que faz com que políticas públicas sejam delegadas a órgãos independentes (nacionais e internacionais), mantendo, teoricamente, as políticas públicas distantes das regras eleitorais, dentre outros. Paradoxalmente, entretanto, esse mesmo contexto gerou políticas públicas de participação social, por meio de experiências alternativas, fóruns, conferências, conselhos, muitas vezes implementadas por organizações não governamentais.

Outros estudiosos apontam, ainda, que a consolidação das avaliações de larga escala de escolas, redes escolares e/ou de sistemas de ensino - realizadas com base em dados extraídos de metodologias estatísticas sofisticadas - e sua utilização como únicos indicadores que apontassem a qualidade do ensino ofertado, constituiria um processo muito diferente de desenvolvimento de estudos na área da avaliação de políticas educacionais, campo mais amplo e complexo no que tange aos propósitos e desenhos metodológicos (BRANDÃO, 2000).

Conforme analisam ainda Martins e Sousa (2012), estudos que lançam mão de dados estatísticos com vistas a estabelecer relações entre desempenho de alunos, perfil e modelos de gestão escolar, devem ser vistos com cautela, pois o delineamento assumido nessas pesquisas, ao tempo em que permite aquilatar fatores que influenciam as trajetórias de escolarização de alunos, articulando-os à gestão da escola e/ou ao perfil de diretores, pode limitar a própria concepção de gestão e de sua qualidade à proficiência de alunos em avaliações em larga escala, desvelando uma visão linear.
9 Atualmente, não é incomum nos estudos da área de políticas educacionais, encontrarmos termos como stakeholders, utilizado em administração estratégica de empresas para analisar as relações da organização com o usuário ou público-alvo. 


\section{CONSIDERAÇÕES FINAIS}

Analisar políticas públicas nesse contexto complexo e multifacetado não é tarefa simples, pois a construção do conhecimento - em qualquer campo - provoca deslocamentos de interesses específicos e de zonas de conforto teórico-metodológicas já instaladas, promovendo paradoxos.

Muitos estudiosos não se sentem à vontade para se aventurar em desenhos que suscitem diferentes e inovadoras abordagens na investigação dos problemas de sua área. Outros pesquisadores, entretanto, adentram e percorrem novos caminhos investigativos, contribuindo para redirecionamentos científicos muitas vezes questionáveis no momento em que são engendrados, mas que podem, no decorrer de um determinado tempo, se configurar como rompimentos necessários às visões anteriormente estabelecidas. Senão vejamos.

No campo da história da ciência, esse movimento - de se examinar a tensão permanente entre a ciência estabelecida e a "ciência em vias de se fazer" - tem sido bastante explorado. Moles (1995), em seu ensaio acerca das ciências do impreciso (compreendidas no amplo campo das ciências humanas e sociais), assinala que entre a primeira e a segunda vertentes há uma muralha de verdades científicas sacralizadas, com base na qual outras verdades passam a disputar espaço e legitimidade. Tomando como ponto de partida a análise do surgimento da ciência moderna - baseada em princípios e leis que moldaram o campo do que se convencionou denominar "ciências exatas" - o autor instiga os pesquisadores a questionar as medidas de precisão no contexto da imprevisibilidade do cotidiano:

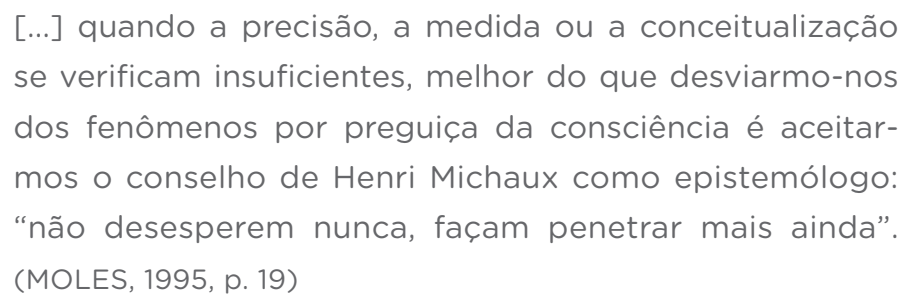

Não se trata de desprezar, portanto, o conceito de predição, bem elucidado pelos estatísticos, mas de reconhecer o erro relativo, a imperfeição provisória dentro da 
predição, com vistas a se estabelecer articulações necessárias e ponderadas entre o que pode ser medido e o que pode ser compreendido, interpretado e/ou analisado de forma mais flexível, talvez, com base em aprofundamentos qualitativos.

De qualquer forma, acrescente-se a essas questões apontadas a complexidade que envolve as opções metodológicas em busca da construção de um conhecimento que mais se aproxime da verdade científica. No campo das ciências sociais esse tema tem sido bastante explorado e, conforme esclarece Bourdieu (2005, p. 83), "se existe uma verdade, é que a verdade é um lugar de lutas”.

Em outra obra e na mesma perspectiva, Bourdieu, Chamboredon e Passeron (2005, p. 14), ao analisarem a constituição do habitus na profissão do sociólogo, salientam que,

[...] à tentação [...] de transformar os preceitos do método em receita de cozinha científica ou em engenhocas de laboratório, só podemos opor o treino constante da vigilância epistemológica que, subordinando a utilização de técnicas e conceitos a uma interrogação sobre as condições e limites de sua validade, proíbe as facilidades de uma aplicação automática de procedimentos já experimentados e ensina que toda operação, por mais rotineira ou rotinizada que seja, deve ser repensada, tanto em si mesma, quanto em função do caso particular.

Na sequência, recomendam, ainda, aos que levam a "preocupação metodológica até a obsessão" (BOURDIEU; CHAMBOREDON; PASSERON, 2005, p. 15), que tomem cuidado para não se transformarem no doente analisado por Freud que limpa constantemente os óculos, porém, sem nunca colocá-los.

Em outros termos, todas as áreas do conhecimento estão sujeitas aos riscos que envolvem qualquer opção metodológica, atingindo estudiosos dos diversos campos científicos. O que dizer, então, de uma área do conhecimento ainda em construção - como é o caso das políticas públicas - considerada por muitos autores como uma subárea tributária da ciência política? Ademais, como analisar a construção do conhecimento - com seus desafios, riscos, limites e 
potencialidades - em uma área que precisou se diferenciar da administração pública, tendo em vista a busca de superação dos desenhos de investigação adotados nos cursos de administração de empresas? Assim, como não teríamos problemas na análise de políticas públicas educacionais, considerando-se que os aportes teóricos da educação advêm da antropologia, da sociologia, da psicologia, da ciência política, da economia, da econometria, da linguística e da história?

Contudo, a renovação do interesse no campo da análise de políticas educacionais por modelos estatísticos que possam explicar resultados, sucessos, fracassos, eficácia e/ou eficiência de programas e projetos, deve ser vista com a cautela necessária para acompanhar mudanças nas dinâmicas que envolvem a produção do conhecimento na área, tendo em vista os elementos que permeiam esse processo, dentre outros: a adoção de um modelo em detrimento de outros, pois substituições de modelos/tipologias não são automáticas e nem geram novidades/verdades/resultados inquestionáveis (esse processo é relativo, como foi dito anteriormente); os recursos destinados a estudos de grande porte - que não podem se restringir aos objetivos de pesquisas demandadas.

Outro problema a ser enfrentado diz respeito às denominadas "pesquisas em rede". Recentemente, algumas agências de fomento têm destinado recursos razoáveis para pesquisas realizadas em redes de pesquisadores, um dos critérios fundamentais para avaliação de programas de pós-graduação estabelecido pela Capes. Esse movimento, talvez, deva se revestir de maiores cuidados, pois na área das ciências humanas e sociais - diferentemente do que ocorre nas ciências físicas e biológicas - não é tão simples compartilhar conceitos, noções e pensamentos. A divulgação de resultados, por exemplo, pode ter elementos complicadores, tendo em vista que se trata de conteúdos e/ou sínteses analíticas de um único problema/objeto, envolvendo um número grande de pesquisadores. Publicar artigos nos periódicos mais qualificados da área com cinco autores já constitui um elemento complicador.

Provavelmente, alguns formatos possam ser mais testados, tais como, estudos de caso formulados preliminarmente, ou 
como estudos-piloto, para aprofundamentos posteriores; a sistematização e análise de dados estatísticos que permitam a emergência de questões a serem exploradas em etapas subsequentes, com base em enfoques qualitativos bem delineados; etc. Desenhos estatísticos sofisticados são bem vindos - sobretudo diante das tecnologias de informação que permitem e facilitam o acesso e o processamento de dados fundamentais -, entretanto, devem ser orientados por uma boa questão e sustentados por uma análise baseada em sólidas teorias.

Em suma, qualquer que seja o modelo adotado, sem um bom embasamento teórico e a devida atenção a ser dada aos pressupostos colocados no início da construção da disciplina - referentes às relações entre Estado, sociedade e política ou, em outros termos, às relações entre polity e politics-, torna-se mais difícil o desafio de se avançar na construção de conhecimentos significativos nesse campo.

\section{REFERÊNCIAS}

AZEVEDO, J. M. L. A Educação como política pública. Campinas: Autores Associados, 2004.

AZEVEDO, J. M. L.; AGUIAR, M. A. S. Políticas da educação: concepções e programas. In: WITTMANN, L. C.; GRACINDO, R. V. (Coord.). O Estado da arte em política e gestão da educação no Brasil: 1991 a 1997. Brasília: ANPAE; Campinas: Autores Associados, 2001. p. 71-87.

BALL, S. La Micropolítica de la Escuela. Madri: Paidós; MEC, 1989.

Sociologia das políticas educacionais e pesquisa crítico-social: uma revisão pessoal das políticas educacionais e da pesquisa em política educacional. Currículo Sem Fronteiras, Rio de Janeiro, v. 6, n. 2, p. 10-32, jul./dez. 2006.

BRASIL. Governo. Melhoria da Gestão Pública por Meio da Definição de um Guia Referencial para Medição do Desempenho da Gestão e Controle para o Gerenciamento dos Indicadores de eficiência, eficácia e de resultados do Programa Nacional de Gestão Pública e Desburocratização - Produto 4 - Guia Referencial para Medição de Desempenho e Manual para Construção de Indicadores. Brasília: Ministério do Planejamento/Secretaria de Gestão, 2009.

BOBBIO, N. O Futuro da democracia. Tradução de Marco Aurélio Nogueira.

7. ed. rev. ampl. São Paulo: Paz e Terra, 2000.

BOURDIEU, P. Razões práticas : sobre a teoria da ação. Campinas: Papirus, 2005. 
BOURDIEU, P.; CHAMBOREDON, J. C.; PASSERON, J. C. Ofício de sociólogo: metodologia da pesquisa na sociologia. Petrópolis: Vozes, 2005.

BRANDÃO, Z. Fluxos escolares e efeitos agregados pelas escolas. Em Aberto, Brasília, v. 17, n. 71, p. 41-48, jan. 2000.

FARIA, C. A. P. Ideias, conhecimento e Políticas Públicas: um inventário sucinto das principais vertentes analíticas recentes. Revista Brasileira de Ciências Sociais, São Paulo, v. 18, n. 51, p. 21-30, fev. 2003.

FIGUEIREDO, M.; FIGUEIREDO, A. M. C. Avaliação política e avaliação de políticas: um quadro de referência teórica. Análise e Conjuntura, v. 1, n. 3. p. 107-127. Belo Horizonte, 1986.

FREY, K. Políticas públicas: um debate conceitual e reflexões referentes à prática da análise de políticas públicas. Revista Planejamento e Políticas Públicas, Brasília, n.21, p. 212-279, jun. 2000. Disponível em: http://desafios2.ipea.gov. br/ppp/index.php/PPP/article/viewFile/89/158. Acesso em: 12 out. 2010.

HAM, C, HILL, M. The Policy process in the modern capitalist state. Londres: Harvester Wheatsheaf, 1993.

MAINARDES, J.; FERREIRA, M.; TELLO, C. ANÁLISE DE POLÍTICAS: fundamentos e principais debates teórico-metodológicos. In: MAINARDES, J.; BALL, S. (Org.). Políticas educacionais: questões e dilemas. São Paulo: Cortez, 2011. p. 143-175.

MARTINS, A. M. (Org.). Estado da Arte: gestão, autonomia escolar e órgãos colegiados (2000-2008). Brasília: Líber Livros, 2011a.

. A Pesquisa na área de política e gestão da educação básica: aspectos teóricos e metodológicos. Educação e Realidade, Porto Alegre, v. 36, p. $45-57,2011 b$.

MARTINS, A. M.; SOUSA, S. Z. A produção científica sobre avaliação educacional e gestão de sistemas e de escolas: o campo da questão entre 2000 e 2008. Ensaio - Avaliação em Políticas Educacionais. Rio de Janeiro, v. 20, p. 9-26, 2012.

MOLES, A. A. As Ciências do impreciso. Rio de Janeiro: Civilização Brasileira, 1995.

O’DONNELL, G. Contrapontos: autoritarismo e democratização. São Paulo: Vértice, 1986.

Transições, continuidades e alguns paradoxos. In: REIS, F. W.; O’DONNELL, G. (Org.). A Democracia no Brasil: dilemas e perspectivas. São Paulo: Vértice, 1988. p. 41-71.

Análise do autoritarismo burocrático. Rio de Janeiro: Paz e Terra, 1990.

OLSON, M. The logic of collective action. Cambridge, Massachussets: Harvard University, 1965.

OZGA, J. Investigação sobre Políticas Educacionais. Porto: Porto, 2000.

PAIVA, V. Pesquisa educacional e decisão política. In: WARDE, M. (Org.). Novas políticas educacionais: críticas e perspectivas. São Paulo: PUC-SP, 1998. p. $125-137$. 
SOUZA, C. "Estado do Campo" da pesquisa em políticas públicas no Brasil. Revista Brasileira de Ciências Sociais, São Paulo, v. 18, n. 51, p. 69-79, fev. 2003.

. Políticas públicas: uma revisão da literatura. Revista Sociologia, Porto Alegre, ano 8, n. 16, p. 20-45, jul./dez. 2006,. Disponível em: <http://www. scielo.br/pdf/soc/n16/a03n16.pdf $>$. Acesso em: 21 set. 2011.

WITTMANN, L. C.; GRACINDO, R. V. (Coord.). 0 Estado da arte em política e gestão da educação no Brasil: 1991 a 1997. Brasília: Anpae; Campinas: Autores Associados, 2001.

\section{ANGELA MARIA MARTINS}

Pesquisadora da Fundação Carlos Chagas. Professora do Curso de Mestrado em Educação da Universidade Cidade de São Paulo (Unicid)

amartins@fcc.org.br 